\title{
Los agentes del libro incunable salmantino (1483-1510)
}

\author{
Vicente BÉCARES BOTAS \\ (Universidad de Salamanca)
}

\section{Resumen}

El objetivo principal de este artículo es presentar los documentos del archivo capitular de Salamanca relativos a las primeras imprentas salmantinas y contribuir a la solución de la «misteriosa» cuestión del anonimato de sus dueños, al conocimiento de los libreros de la primera época y al oscuro papel de Nebrija en este asunto.

Palabras clave: Salamanca, Incunables, Impresores, Libreros, Nebrija.

\section{The Makers of Incunabula at Salamanca}

\section{Abstract}

The main subject of this article is to present the papers of cathedral's archives at Salamanca concerning the primitives local printing offices and to contribute to the hitherto «misterious» question of the anonymity of their owners, to the notice of the early salmantine booksellers and to the Maestro Nebrija's shady role in this matter.

Keywords: Salamanca, Incunabula, Printers, Booksellers, Nebrija 
Aunque desde siempre - como no podía ser menos- se ha reconocido su valor instrumental, y se han beneficiado los archivos como fuente de la historia (la general y la del libro en particular), la evidencia nos dice que demasiado a menudo la investigación - en nuestras ciencias humanas digono procede desde la búsqueda de datos primarios, sino, a la inversa, se prefiere - por inexistencia de los mismos o por preterición- partir de «exhaustivas» pesquisas bibliográficas o de «sólidas» hipótesis de trabajo, que luego los hechos se encargarán de confirmar (y muchas veces de desmentir).

Por lo que se refiere a la historia del libro, es un hecho que se ha basado más en la bibliografía material y en los paratextos que en la evidencia documental; son muy pocas las ciudades que cuentan con los fundamentos básicos de unos documentos para la historia de la imprental librería en..., al menos de sus primeros vagidos, como Barcelona o Zaragoza. Nada digamos si pasamos del ámbito público de los archivos notariales civiles (que suelen faltar para esas etapas primitivas) y nos adentramos en los eclesiásticos (no siempre accesibles). Cuando éstos no estaban disponibles clamaban al cielo los investigadores y cuando lo han estado la formación tecnocrática actual y preferente los deja en las vías muertas del interés y la accesibilidad. Hemos de reconocer que los tiempos de los Pérez Pastor, Catalina García, Madurell Marimón, García Chico, Serrano y Sanz, Espinosa Maeso, etc, han pasado. Aunque tal vez seríamos injustos si no mencionásemos algún epígono entusiasta, como Pedraza Gracia en Zaragoza o Rojo Vega en Valladolid-Medina del Campo.

En el caso del libro incunable salmantino, cuando se trataba del extraño anonimato de los primeros talleres y de la titularidad de sus dueños, que era el misterio a desvelar, tuvo que ser una historiadora (no del libro) la que se topase con un par de documentos de la Real Chancillería de Valladolid y arrojase un poco de luz sobre el no resuelto enigma de sus primitivas imprentas. ${ }^{1}$ Es verdad que años antes algún benemérito, catedrático o archi-

\footnotetext{
*Le agradezco al archivero Raúl Vicente Baz su disponibilidad y ayuda.

${ }^{1} \mathrm{M}^{\mathrm{a}}$. A. VARONA GARCÍA, «Identificación de la primera imprenta anónima salmantina», Investigaciones Históricas. Época Moderna y contemporánea 14, 1994, 25-33. Id., Cartas ejecutorias del Archivo de la Real Chancillería de Valladolid, Valladolid, 2001.
} 
vero $^{2}$ (tampoco historiadores del libro) habían pasado la mirada sobre los documentos pertinentes, pero como su móvil solía ser otro, acuciados como estaban por otras preocupaciones: aquí el acopio de documentos, allí temas y querellas localistas (siete ciudades se disputan la gloria de Homero), pasaron de puntillas sobre nuestro asunto. ${ }^{3}$ El benemérito P. Méndez se extrañó de la ausencia de ejemplares incunables en la Biblioteca universitaria, y no solo salmantinos, lo que no era cierto, sino la consecuencia de no utilizar las fuentes adecuadas o de utilizarlas inadecuadamente. ${ }^{4} \mathrm{Y}$ los no menos dignos de memoria: R. Proctor, K. Haebler, F. Vindel, L. Cuesta, F. Norton, A. Odriozola, C. Romero de Lecea, L. Ruiz Fidalgo, bibliógrafos e historiadores lato sensu de los orígenes de la imprenta, no trabajaron (que yo sepa) en archivos de Salamanca. En fin, a quien esto escribe, tampoco bibliógrafo legal (antes bien preocupado por, y ocupado en, la extensión e intensidad del Humanismo en nuestra tierra y sus relaciones de dependencia con el libro áureo), una simple asociación de ideas —que no arduo ni nuevo razonamiento- le permitió ampliar su círculo de búsqueda archivística (además de los notariales y parroquiales, de largo peregrinar $)^{5}$ e incluir los archivos catedrales, a menudo con fondos más antiguos y menos lagunosos: si los Cabildos eran los dueños de los espacios «industriales» del libro o encargaban

2 D. Ricardo Espinosa Maeso, catedrático de Filología griega, autor de un formidable archivo personal de tema salmantino; el sacerdote y archivero D. Florencio Marcos; D. Manuel García Blanco, catedrático de Gramática Histórica, etc.

${ }^{3}$ F. MARCOS, «En el V Centenario de la introducción de la imprenta en España», El Adelanto (29 de diciembre de 1974, p. 17); reimpreso en Historias y leyendas salmantinas, 1987 (1982), «Salamanca y las primeras prensas españolas», p. 251-255. Fue contestado de inmediato por C. ROMERO DE LECEA en el mismo periódico local El Adelanto el 31 de enero de 1975, p. 12, y 4 de febrero siguiente, p. 3. Pero los títulos disponibles eran de este tenor «Barcelona fue la primera ciudad de España donde se introdujo la imprenta» (J. RIPOLL), «La imprenta de Zaragoza es la más antigua de España» (M. SERRANO y SANZ), «El incunable barcelonés de 1468» (R. Miquel y Planas), «Primer libro impreso en España. Les trobes en lahors de la Verge María» (MARTí GrajALES), «Les trobes... Noticias sobre la impresión del primer incunable español» (IBARRA y FOLGADO), «El Sacramental sevillano de hacia 1470» (F. VINDEL), el V Centenario de la imprenta en España 1474-1974, Tarragona, 1974, etc. La querella venía de lejos: A. MESTRE SANCHís, Los ilustrados, el origen de la imprenta y el catálogo de incunables españoles, Valencia, 2007. Ver también J. MARTíN ABAD, «La primera imprenta anónima salmantina (1480-1494), últimos hallazgos y algunas precisiones», en Calligraphia et tipographia. Arithmetica et numerica. Chronologia, Barcelona, 1998, 437-458. Id. Los primeros tiempos de la imprenta en España (c. 1471-1520), Madrid, 2003, p. 66ss, donde vuelve sobre esa «única» imprenta. Curiosamente, al día de hoy, siguen circulando los mismos tópicos localistas por la red y fuera de ella. Contra, por ej., Juan Párix, primer impresor en España, Segovia, 2004.

4 Tipografía española, p. XIIIs: «En prueba del poco aprecio que se ha hecho de las ediciones del siglo XV se puede alegar las poquísimas que de dicho siglo se encuentran en la Biblioteca de la insigne universidad de Salamanca...»

5 Véanse mis Guía documental del mundo del libro salmantino del siglo XVI, Segovia, 2006; Librerías salmantinas del siglo XVI, Segovia, 2007. 
los litúrgicos de sus Diócesis respectivas, en los registros de sus actas y cuentas tendrían que recogerse los arrendamientos, acuerdos, conciertos y libramientos consiguientes a libreros e impresores. Y, con el señuelo de esa idea, ${ }^{6}$ hacia allí dirigí los pasos (no muchos a decir verdad, pues enfrente de la Facultad tenía (-mos) la(s) Catedral(es). ${ }^{7}$

Lo que sigue es, pues, el resultado de la búsqueda (a los datos me remito, que otros valorarán con más tino) y la conclusión: el historiador del libro que haya de resolver cuestiones relativas a la cuna del impreso, en la ciudad que sea, y a los albores de su difusión, tendrá que ampliar, al menos por estos pagos, su circuito de investigador y añadir a sus pesquisas la documentación capitular en al menos estas tres series de testimonios:

a) Libros de actas: recogen todos las disposiciones y expedientes relativos al funcionamiento del Cabildo (se celebraban tres días por semana: lunes, miércoles y viernes, a la salida de misa de prima); en particular interesan los acuerdos sobre la administración patrimonial: arrendamiento de casas, fianzas, conciertos y contratos de toda suerte, etc. En Salamanca arrancan de 1295.

b) Libros de fábrica: especifican todas las cuentas y libramientos por servicios efectuados a la Catedral, entre ellos, obvio, la adquisición de libros litúrgicos; en Salamanca comienzan, lástima, en 1499 (a pesar de su mal estado, hoy ya consultables después de haber sido restaurados y digitalizados).

c) Libros de rentas y propiedades: en Salamanca el primero escrito hacia 1500 (pero registran los datos de los arrendamientos existentes en esa fecha, o sea, de inquilinos anteriores, como se verá más abajo). Por ellos es posible seguir la ocupación sucesiva de las casas propiedad del Cabildo (lo era la mayoría en los alrededores de la Catedral y de la Universidad, y muchas de ellas, como es natural en nuestro caso, ocupadas por las gentes del libro).

Y todo ello podrá, y deberá, completarse con otras series documentales (Libros de fundaciones de memorias de aniversarios, etc) y cruzarse con los libros similares de diócesis limítrofes cuando un centro impresor cualquiera trabaje, lo que era frecuente, para territorios colindantes, como en el caso de Salamanca, con las de Ávila, Ciudad Rodrigo, León, Zamora, Braga u Orense.

El propósito de estas líneas se cumple, creo que razonablemente, con la presentación de los documentos, dejando para los incunabulistas e

\footnotetext{
${ }^{6}$ No deben confundirse los Archivos Capitulares y los Parroquiales. Por ejemplo, M. J. PeDraza GRACIA, El libro español del Renacimiento. La "vida" del libro en las fuentes documentales contemporáneas, Madrid, 2008, sólo hace referencia a la documentación parroquial, p. 33. Sin embargo, por documentos capitulares había probado la existencia de un fantasmal Missale Compostellanum A. López Ferreiro, Historia de la A. M. Iglesia de Santiago de Compostela, 2 v., Santiago, 1898-1911. (Ver además VINDEL, nº 78; ODRIOZOLA, nº 59).

7 Ahora es posible disponer de una sólida guía del mismo: P. J. GÓMEZ GONZÁLEZ y R. Vicente BAZ, Guía del Archivo y Biblioteca de la Catedral de Salamanca, Salamanca, 2007. Como ejemplo del provecho del método, ver $\mathrm{M}^{\mathrm{a}}$ del C. Álvarez MÁrQuEZ, El mundo del libro en la Iglesia Catedral de Sevilla en el siglo XVI, Sevilla, 1992.
} 
historiadores del libro en ejercicio las interpretaciones y conclusiones que les permitan aclarar esos oscuros (por enigma y misterio tenidos) primeros momentos de la imprenta salmantina, pues a ellos les compete. Sólo que el capítulo inicial ya no podrá comenzar de modo tan desolador como hasta ahora: «La historia de la imprenta en Salamanca, en el siglo XV, no está del todo clarificada. Se debe en buena parte a una carencia casi absoluta de datos documentales, pero principalmente a la continuada anonimia de los impresores». ${ }^{8} \mathrm{Ni}$ lo uno ni lo otro, lo que la hacía campo abonado para la natural libido conjiciendi del investigador. Así, se pensó en Nebrija como el propietario del primitivo taller de imprenta; Proctor, Haebler, Norton, Vindel, Martín Abad, Ruiz Fidalgo, etc, aceptan la existencia de un sólo impresor que renueva sus tipos ( $\mathrm{y}$ el anonimato por la falta de competencia, es decir, rivalidad en el oficio, o por la incompatibilidad con su cargo profesoral en el caso de Nebrija); Romero de Lecea llegó incluso a poner nombre al tapado: el sevillano Pablo de Colonia, eso sí «pero no puedo aportar testimonios definitivos sobre la cuestión planteada, pues se desconoce la existencia de documentos que permitan tener por incontrovertida la solución propuesta». ${ }^{9}$ Ahora sabemos que fueron al menos (pues el genérico «librero» no permite aquilatar más) cinco ${ }^{10}$ las imprentas (o sociedades) neonatas y que sus conocidos propietarios rivalizaban de verdad por la adjudicación de los encargos, a saber:

Diego Sánchez de Cantalapiedra y Alfonso de Porras (hasta 1487-88),

Juan de San Vicente y Rodrigo de Escobar, «moldero»,

Pedro de Salaya y Juan de Montejo,

Juan de Montejo y Juan de Porras,

Juan de Porras, él sólo a partir de 1491. Murió el 22-11-1527.

Además de un oficial de imprenta, operario en alguna de ellas: Bartolomé de Vadillo, ofiçial de los moldes (¿con Juan de Porras? Ver $\mathrm{n}^{\circ} 7$ y 8 infra). Más varias mujeres libreras o libreras-impresoras, si nos atenemos al oficio de sus parientes, como Catalina González de Valdivieso, mujer de Diego Sánchez de Cantalapiedra, pleiteante con Juan de Porras, hijo de Alfonso de Porras; Leonor, hija de Diego Alonso, mujer de Juan de Porras; Elvira Ruiz de San Vicente, hija de Juan de San Vicente, casada con Bartolomé de Francaforte (¿alemán?).

Por documentos fehacientes emanados, bien de pleitos civiles o de los eclesiásticos que estamos considerando, podemos saber asimismo que el

8 F. J. NORTON, La imprenta en España 1501-1520 (anotada por J. Martín Abad), Madrid, 1997, p. 55.

9 C. Romero DE LECEA, «Consideraciones sobre la imprenta anónima incunable de Salamanca», Homenaje a Pedro Sainz, Rodríguez: Tomo III: Estudios históricos, Madrid, 1986, 603-619. Id., «En el V centenario de la imprenta de Sevilla», en el Libro homenaje a Antonio Pérez Gómez, Cieza, 1978, v. II, 113-132.

${ }^{10}$ Seis, si contamos la de Leonardo Hutz y Lope Sanz de finales del siglo. Siete, con Gysser (1500-09). 
número de libreros de la edad incunable conocidos bien pudo llegar a, y superar, la veintena. Es el caso que en 1502 estalla un conflicto entre los libreros y el Concejo con su corregidor al frente, don Diego Osorio, al recurrir los primeros la sentencia contra ellos dada a favor de la dicha ciudad por la cual les mandaron contribuir y pechar en los repartimientos que se fazen por los juegos de Corpus Christi; ${ }^{11}$ el gremio librero trató de acogerse al fuero universitario, porque

siempre han sido e son avidos e tenidos e comunmente reputados por miembros e personas de la dicha Universidad e Estudio de la dicha çibdad e han gozado e acostumbrado gozar de todas las prerrogativas e ynmunidades e esençiones de que gozan los mesmos estudiantes de la dicha Universidad e que asi se ha usado e acostumbrado desde el dicho tiempo ynmemorial a esta parte, y porque agora viven e residen en la dicha ciudad de Salamanca $e$ han tenido e agora tienen sus tiendas de libros $e$ enquadernaçiones para serviçio de la dicha Universidad e Estudio;

lo más interesante para nosotros es que las procuraciones consiguientes nos detallan los nombres de los agremiados; en la primera se nombran: Alonso de Almenara, Sebastián y Juan Sánchez, Fernando y Juan librero, Diego librero, Bartolomé y Juan Vázquez, Diego de Portillo, Juan Martín, Pedro de Mansilla, libreros y encuadernadores; para la segunda procuración se nombra a Tomé, Antonio, Francisco, Juan librero, Bertolo, Ferrando e Alonso de Almenara, Diego, Juan Sánchez, Pedro de Mansilla, Luis Fernández, Sebastián, Francisco, Diego Martínez, Juan Martín, Simón Gil, Diego de Portillo, Alonso Nieto, todos enquadernadores veçinos de la noble çiudad de Salamanca. ${ }^{12}$ A muchos de ellos los veremos de nuevo en la documentación abajo transcrita.

Sin contar con que para entonces las redes europeas, veneciana y lyonesa, de distribución del libro se hallaban perfectamente instaladas en las ferias de Medina - Salamanca, como prueba la presencia por esas fechas de los Castronovo, Liondedei, Rosiñolis, Lecarón, etc. ${ }^{13}$

Por el contrario, poco es lo que confirman los documentos de las opiniones más asentadas sobre Nebrija y la imprenta - librería salmantina: el maestro de Lebrija anduvo ocupado a lo largo de su larga vida en otros menesteres (no excluyentes ni incompatibles, cierto) y lugares, y ausente de Salamanca entre 1487 y 1505, y desde 1513 hasta su muerte en 1522. Añádase, por paradoja, la escasa, «casi» nula, mención que en estos documentos hemos encontrado de los «conocidos» Lope Sanz y Leonardo Hutz en 1496, o del «fundidon» Gysser, ya en Salamanca con tipos nuevos (para Juan de Porras) en 1500, los últimos en sacar de pañales, incunabula, al libro salmantino. Ahora

\footnotetext{
11 Por cierto, en el de 1508 un Cristóbal de Rueda y compañía representaron el abto de fortuna en el que aparecían «el Rey e la Reyna e el hermitaño con el paston».

12 Archivo de la Real Chancillería de Valladolid. Quevedo (F), C $C^{a}$ 1430-2: «Proceso de los libreros de Salamanca contra la ciudad.»

13 V. BÉCAREs BotAS, La compaña de libreros de Salamanca (1530-1534), Salamanca, 2003. Id., Guía documental del mundo del libro salmantino del siglo XVI, Segovia, 2006.
} 
bien, poco eco parece haber tenido la conclusión de Varona García: «En algunos casos la identificación es segura, ya que hoy sabemos que algunos de los más famosos incunables que los tratadistas reconocen como obras de la "primera imprenta anónima salmantina", en realidad salieron de los talleres de Cantalapiedra-Porras». ${ }^{14}$

Por tanto, sin más preámbulos encarecedores, mi objetivo particular para la ocasión (al no ser bibliógrafo de facultad) lo considero suficientemente cumplido: adelantar los testimonios que permitan arrojar alguna luz sobre el alba del libro impreso y su difusión en nuestro centro humanístico más conspicuo, ${ }^{15}$ como cabía esperar de su estatus sobresaliente en el concierto y concento universitario de la época; un mundo revolucionado en todos sus aspectos por el recién nacido invento $\mathrm{y}$, a su zaga, por el comercio de librería, ${ }^{16}$ no siempre fáciles de distinguir, por deficitarias que resultasen una y otra para las necesidades de aquél, pero demasiado obvio y presumible para poder ocultarse. Cinco mil estudiantes, y los profesores en proporción, demandantes del producto humanístico por excelencia, por no hablar de sus efectos, la implantación del Renacimiento, lo hacían suponer. ${ }^{17}$ Ahora conocemos por sus nombres y domicilios al menos una parte, sin duda, de lo que debió ser la realidad librera salmantina en los inicios de los tiempos modernos. Para ello he transcrito o extractado el medio centenar de asientos referidos a impresores - empresarios- (molderos) y libreros que una lectura nada fácil me descubría en los Libros Capitulares susodichos, con unos mínimos comentarios aclaratorios en nota. Se extienden desde 1404, primera mención de un librero salmantino, pero sobre todo desde 1483, primera mención de Diego Sánchez de Cantalapiedra ( $n^{\circ}$ 6), hasta 1510, más o menos, fecha límite del interés para nuestro propósito.

En cursiva van los asientos de los libros transcritos a la letra; en redonda meros extractos del contenido.

I. Libros de Actas Capitulares (AC) correspondientes al siglo XV:

\footnotetext{
${ }^{14}$ Cit. p. 31s.

15 Que no es el dibujado, por ejemplo, por M. de la MANO GonZÁLEZ, Mercaderes e impresores de libros en la Salamanca del siglo XVI, Salamanca, 1998.

16 Los libros impresos tuvieron que llegar a Salamanca, como es lógico, antes que la imprenta. En la biblioteca del obispo D. Gonzalo de Vivero había ya libros de molde el 27 de enero de 1480 (la Reynerina de molde, el libro Astense), fecha de su testamento; no digamos en la de D. Juan de Castilla, muerto el 12-10-1510 (del tema de las bibliotecas particulares salmantinas en esta época ya nos hemos ocupado y lo haremos público en otro momento). Nebrija, en Salamanca desde 1473 como docente, Arias Barbosa y tantos otros profesores, por fuerza tuvieron que conocerlos en Italia y, con seguridad, poseerlos. De las bibliotecas de los Colegios Mayores se conservan inventarios manuscritos del siglo XV del de San Bartolomé.
}

17 J. L. MARTín, El patrimonio de la Catedral de Salamanca, Salamanca, 1985, p. 325: «Más de catorce familias vivían en Salamanca [a finales del XV] de esta actividad [ibrera]». 
1. AC. $1, \mathrm{f}^{\circ} 153$, antiguo 144 (24 de marzo de 1404):

El Cabildo hace merced a Jacob, ${ }^{18}$ librero, para que pague las rentas en tres plazos: el primero de julio, el primero de noviembre y el primero de marzo. En el mismo folio aparece un acta tachada con el mismo contenido.

2. AC. $2, \mathrm{f}^{\mathrm{o}} 10 \mathrm{v}$ (20 de octubre de 1413):

Renta de Gonzalo Moro, ${ }^{19}$ librero, de unas casas a la Puerta del Río. Vuelve a ser mencionado con este oficio en los Cabildos de 3 de junio de 1415 y de 29 de enero de 1416.

3. Id. fo $84 \mathrm{v}$ :

Renuncia del racionero Fernando Álvarez de las casas en el Desafiadero, ${ }^{20}$ cerca de las casas en que vive Gonzalo Moro, librero, ${ }^{21}$

4. AC. $7, \mathrm{f}^{\circ}$ 66r (15 de enero de 1483): Fiança de unas casas que tiene María Gonçález, muger de Esteban Fernández, peraire.

Fernando González, librero, queda por fiador de la renta y reparos de las casas que tiene María González, mujer de Esteban Fernández (peraile / pelaire, o sea, pañero), en la calle de Escuderos.

5. Id. fo 67r: Renuncia de las casas que tiene Bernal, librero.

El bachiller Martín Fernández de Treviño, racionero, salió por fiador de la renta y reparos de las casas que tiene Bernal, ${ }^{22}$ librero, donde vive, enfrente del maestrescuela.

(Éste debía de ser Tomé Bernal).

6. AC $8, f^{0} 31 \mathrm{v}$ (22 de diciembre de 1483):

Este dicho día e cabildo fiçieron graçia a la de Diego Sánchez de Cantalapiedra ${ }^{23}$ de siete mil e quinientos maravedís corrientes que fico de mejoría en las casas que tiene cabe el

\footnotetext{
18 Supongamos que fuera judío, si bien, lógicamente, su religión es irrelevante para los efectos.

19 ¿Sería éste musulmán? Mejor, morisco. A los que siguen los supondremos todos cristianos, viejos o nuevos.

${ }^{20}$ Se llamaba entonces el Desafiadero a la prolongación hacia el poniente, más allá de la Universidad, de la Rúa Nueva o Calle de los Libreros.

${ }^{21}$ Los dos primeros Libros de Actas no están, de momento, disponibles para el público por su mal estado de conservación; debo estos y otros datos, que agradezco, al eficiente archivero Raúl Vicente Baz. El resto de los libros sí los he tenido presentes.

22 Libreros de este apellido siguió habiéndolos en el siglo XVI. Ver mi Guía documental, cit., ver «Bernal».

${ }^{23}$ Es, con Alfonso de Porras, el primer impresor salmantino conocido, procedente, dicen, de Sevilla. ¿Tendría algo que ver la clausura de la primitiva imprenta sevillana en los primeros ' 80 con la apertura de la salmantina en esos años? La mujer se llamaba Catalina
} 
señor obispo de Orense, segund dieron fee Martín Añes, ${ }^{24}$ Arçediano de Medina e el canónigo Juan Martinez que lo avian ydo a ver. Testigos dichos.

¿Hemos de suponer que para entonces había fallecido ya este protoimpresor salmantino?

7. AC 9, fo 85r (28 de junio de 1486): Traspasamiento de la beredad de AldeaRodrigo.

Este dicho día e cabildo paresçió Gonçalo Pérez, Raçionero, e dentro de los treinta días traspasó en Bartolomé de Vadillo, ofiçial de los moldes, que presente estava, las dos yugadas y media de heredad e dos casas e un pajar que él tenía en renta de los dichos señores deán e cabildo...

8. AC 10, fo 17v (31 de julio de 1486): Fiança de la heredad de AldeaRodrigo.

Este dicho día e cabildo Antón Calderero $v^{\circ}$ de la dicha çibdad quedó por fiador de Bartolomé de Vadillo, oficial de los moldes, de la heredad que tiene del cabildo en Aldearrodrigo e casas por rentas e reparos. Testigos dichos. ${ }^{25}$

9. Id. $\mathrm{f}^{\mathrm{o}}$ 45r (15 de noviembre de 1486):

Juan de Mansilla, ${ }^{26}$ librero, vecino de Salamanca, sale por fiador de unas casas que tiene Juan de Mella.

10. Id. fo 70r (16 de febrero de 1487): Poder

Este dicho día e cabildo dieron poder al bachiller Fernando de Maluenda e a Diego Rodríguez, canónigos, que presentes estaban, para entender e contractar e avenir e igualar con Rodrigo de Escobar, moldero, e con sus compañeros sobre los Misales que se han de façer para este Obispado ${ }^{27}$ e façer con ellos las igualas e preçios e tasas que para la terminaçión dello convenga e llamar a los aqui presentes e conçertar e asentar con ellos lo que bien visto les fuere, e obligaron los bienes de la dicha Iglesia de lo haber por firme e lo qual contradixo el dicho Pedro Fernández de Toro, lugarteniente del deán. Testigos dichos.

11. Id. fo $70 \mathrm{v}$ (19 de febrero de 1487): Poder

Este dicho día e cabildo dieron poder al ldo. Villalpando e a Maluenda e a Diego Rodriguez que presentes estaban para entender en lo de los misales de molde segund e por la forma que estava asentado del viernes pasado. Testigos dichos.

12. AC 11, f f $^{\circ}$ (18 de julio de 1487): Fiança

González de Valdivieso; no sabemos si viuda por estas fechas; los apellidos de ambos parecen, no obstante, de raigambre charra. Ver también ROMERO DE LECEA, cit. supra.

${ }^{24}$ Don Martín Añes (Fáñez), arcediano de Medina y racionero de Salamanca, cura de dicha capellanía, limosnero, del consejo y confesor de la reina doña Isabel, mujer del rey don Juan II. Murió en agosto de 1503.

25 ACSA. 25, f 414 (1520): «María Gutiérrez, mujer que fue de Bartolomé de los moldes».

${ }^{26}$ Un Pedro de Mansilla era librero en 1502. El parentesco, probable.

${ }^{27} \mathrm{Nada}$ se conserva de ellos.

Titivillus, ISSN 2387-0915, ISSN-e 2603-9966, 2 (2016), pp. 81-105 
Este dicho día e cabildo Martín Sánchez, latonero, dio por fiadores de renta e reparos de las casas que tiene a la Rúa Nueva a Pedro de Valderas [sastre] y a Juan, librero, ${ }^{28}$ que presentes estavan; obligáronse con él de mancomún. Testigos dichos.

13. Id. fo $11 \mathrm{r}$ (8 de agosto de 1487) : De los misales

En Salamanca, miércoles, a los ocho días de agosto de ochenta e siete años, estando don Álvaro de Pą, deán, e otras personas, dignidades, canónigos e Raçioneros della ayuntados en su cabildo hordinario, dixeron que por quanto sobre los Misales que se avian de faser para este Obispado avía diferençia entre Juan de San Viçente e Rodrigo de Escobar de la una parte e de la otra Juan de Porras e Juan de Montejo, que asentavan e mandavan e concertavan que los que los quisiesen faser los habian de faser segund e por la forma contenida en los capitulos que están fechos que se han de dar a mí el dicho notario firmados del bachiller Fernando de Maluenda e de Pedro Fernández de Toro e que vistos se ha de conplir todo lo en ellos contenido e que el que los quisiere faser de aqui al lunes en todo el día sea obligado de poner en el sagrario de la dicha Iglesia prendas de plata que valgan çient mil maravedís para que si non conplir lo contenido en los dichos capitulos y en cada cosa e partes dellos, los pierdan e queden aplicados para la fábrica de la dicha Iglesia, y que el que menos los faser con las condiçiones susodichas, fasta día de Santa María a agosto que verná primero fasta puesto el sol, que a aquél se le dé, y esto prometieron de traer e conplir e guardar. Testigos el bachiller Gil Fernández de Tapia e Miguel Fernández, capellán, e Alonso Cornejo, notario.

Este dicho día lo notifiqué a los dichos Juan de San Viçente e Rodrigo de Escobar. Testigos, Pedro de Paz, del deán, e Pedro de V alderas, sastre.

Este dicho día lo notifiqué a los dichos Juan de Porras e Juan de Montejo. Testigos, Antón del Pariso y Gonçalo Garçia, benefiçiados de Palaçios. ${ }^{29}$

14. Id. $\mathrm{f}^{\mathrm{o}} 14 \mathrm{v}$ (7 de setiembre de 1487): Sobre los briviarios. ${ }^{30}$

En Salamanca, viernes siete días de setienbre año dicho, estando don Álvaro de Paz, deán, e otras personas distinguidas, canónigos e raçioneros della, dieron poder conplido al dicho señor deán e a Maluenda e a Pedro Fernández e Diego Rodríguez, canónigos, que presentes estaban, para asentar e conçertar con Juan de Montejo e Juan de Porras sobre los Misales que se han de faser para este Obispado e faser con ellos contracto e asiento. Testigos Miguel Fernández e Antón Bernal. ${ }^{31}$ Alonso Cornejo, notario.

\footnotetext{
${ }^{28}$ Sería este librero el mencionado (9) Juan de Mansilla, pero también hubo otros libreros Juan Vázquez, Juan Martín, Juan de San Vicente.

29 Este documento prueba que, finiquita la de Alfonso de Porras y Sánchez de Cantalapiedra, siguieron funcionado dos nuevas sociedades impresoras: la de Rodrigo de Escobar y Juan de San Vicente, por un lado, y la de Juan de Montejo y Juan de Porras, por otro. Nebrija, que sepamos, estuvo ausente de Salamanca entre 1487 y 1505.

${ }^{30}$ En el pleito que publicó $\mathrm{M}^{\mathrm{a}}$. A. Varona, cit., sí se mencionan «quatrocientos breviaros de la horden e obispado de Salamanca», pero no Misales, aquí el motivo el contrato. De ninguno de ellos ha quedado muestra.
}

${ }^{31}$ Era portero de la Catedral. No sabemos del parentesco con el librero de este apellido.

Titivillus, ISSN 2387-0915, ISSN-e 2603-9966, 2 (2016), pp. 81-105 
15. Id. fo $47 \mathrm{v}$ (5 de marzo de 1488): Poder del mayordomo e cofrades de la confradía de Santa María la Blanca.

... Juan yluminador e Juan de Mansilla, librero, e Rodrigo de Miranda yluminador...

16. AC. 12, f 36 r (7 de enero de 1489): Fiança

Este dicho día e cabildo Alonso Gomes, canónigo, quedó por fiador de la de Bernal, librero, por las casas que tiene frontero del maestrescuela. Testigos dichos.

17. Id. fo 39v (6 de febrero de 1489):

Rodrigo de Escobar, librero, salió por fiador de Benito de Valderas, zapatero, de unas casas a la Puerta del Río, fronteras del mesón de Gibraltar. ${ }^{32}$

18. Id. f $69 \mathrm{v}$ (15 de marzo de 1490):

...junto a las casas de Bernal, librero. ${ }^{33}$

19. Id. $\mathrm{f}^{\mathrm{o}}$ 13r (27 de agosto de 1490): Segundo cabildo de las casas de la calle descuderos.

Este día e cabildo fisieron el segundo cabildo de las dichas casas de la calle descuderos que vacaron por muerte del librero. Y púsolas Pedro de Figueroa en seteçientos maravedís viejos.

20. Id. $\mathrm{f}^{\mathrm{o}} 13 \mathrm{v}$ (30 de agosto de 1490): Postrimero cabildo de la cal descuderos.

El librero de San Sebastián [entiéndase, de la calle de - la iglesia de-San Sebastián, hoy en la Plaza de la Catedral, detrás de la Universidad]. Podría ser Tomé Bernal.

21. Id. fo 28 (27 de septiembre de 1490):

Arriendo de unas casas con dos puertas enfrente de las Escuelas Mayores a Juan de Porras, el de los moldes. Fiador, su suegro Diego Alonso, mercader.

22. Id. $\mathrm{f}^{\mathrm{o}}$ 51r (3 de diciembre de 1490): Fiança

Este dicho día e cabildo Rodrigo de Escobar, librero, ${ }^{34}$ quedó por fiador por rentas e reparos con Andrés Fernández de Machacón, raçionero, por rentas e reparos de unas casas que tiene frontero de las escuelas.

23. AC. 15, fo 9r (22 de octubre de1491): Liçençia

Este dicho día e cabildo dieron liçençia a Juan de Porras $\langle e l>$ de los moldes para labrar en las casas que sacó del bachiller Diego de la Puente, frontero de las escuelas, lo que

32 La calle de Gibraltar existe todavía con este nombre, detrás de la Catedral vieja.

33 Tal vez fuera Tomé Bernal. Tomé librero se ausenta de Salamanca en 1508 (AC. 24, fo 258v).

34 Un bachiller Cristóbal de Escobar es autor de Esta es una introduction muy breve de canto llano, Salamanca, 1496 (VINDEL, El arte..., n ${ }^{\circ}$ 76, p. 116). ¿Serían parientes y la imprenta la de Rodrigo de Escobar?

Titivillus, ISSN 2387-0915, ISSN-e 2603-9966, 2 (2016), pp. 81-105 
dixeron el canónigo Pedro de las Cuevas e Alonso Gomes que la avían ydo a ver. ${ }^{35}$ Testigos dichos.

24. Id. $\mathrm{f}^{\mathrm{D}} 28 \mathrm{v}$ (2 de diciembre1491):

En Salamanca en este dicho día e cabildo fiçieron graçia a Juan de Porras, librero, $e$ su mujer, de mill e çiento maravedís que gastó en las casas e tienda que fiço en la Rúa Nueva, frontero de las Escuelas. Reçibieron en quenta lo que estava fecho en la dicha casa de su muger de Juan de Porras.

25. Id. fo $29 \mathrm{v}$ :

En Salamanca este dicho día el canónigo Pedro de las Cuevas por virtud del poder que ha e tiene de los señores deán e cabildo para lo de yuso escripto, arrendó e dio en Renta a Leonor, mujer de Juan de Porras que presente estaba, unas casas que los dichos señores deán e cabildo han e tienen en la Rúa Nueva de esta dicha çibdad frontero de las escuelas mayores que el dicho Juan de Porras tiene ansi mesmo dellos en renta por su vida y ge las dan a ella por mejorias que ella e el dicho su marido en ellas fisieron de quarenta mill mrs. e non lo fisieron de graçia de mill e çiento mrs. corrientes.

26. Id. fo 63 (9 de abril de 1492):

Juan de Montejo, maestro de los moldes, fiador de Juana de Grado, mujer de Benito de Valderas, zapatero.

27. AC 16, fo 24 (16 de diciembre de 1493):

Primer Cabildo de las casas de la mujer de [Tomé] Bernal, librero.

28. Id. fo $25 \mathrm{v}$ (23 de diciembre de 1493): Postrimero cabildo de las casas de la de Bernal, librero.

En Salamanca, lunes, veynte e tres días de diayenbre de XC y tres años, estando don Álvaro de Paz, deán e otras personas en su cabildo bordinario ... unas casas frontero de las del maestrescuela que vacaron por muerte de la de Bernal, librero... Testigos, Diego Bernal e Antón Bernal e Diego de Medrano.

29. Id. fo 27 (3 de enero de 1494): Postrimero cabildo de las casas de Bernal librero.

Las casas que vacaron por muerte de la mujer de Bernal, librero, pasaron a Alonso de Paz, canónigo.

30. Id. $\mathrm{f}^{\mathrm{O}}$ 30r (24 de enero de 1494): Traspasación de las casas de Bernal librero.

Alonso de Paz, canónigo, traspasó las casas que vacaron por muerte de Bernal, librero, en Tomé, hijo del dicho Bernal, librero. ${ }^{36}$

\footnotetext{
${ }^{35} \mathrm{El}$ asiento es algo confuso. Parece entenderse que le dieron licencia para que instalase la imprenta en las casas del Cabildo. Ver los siguientes asientos.

36 Una Leonor Bernal estuvo casada con el librero Simón de Portes. Ver mi Guía documental..
}

Titivillus, ISSN 2387-0915, ISSN-e 2603-9966, 2 (2016), pp. 81-105 
31. Id. fo $42 \mathrm{v}$ (23 de abril de1494):

Este dicho día e cabildo Pedro de Lilia, ${ }^{37}$ joyero, quedó por fiador de Antonio de la Barreda, librero,,$^{38}$ por rentas e reparos de las casas que tiene a la boca de la Rúa, ejuraron etc. Testigos dichos.

32. Id. f $43 \mathrm{v}$ (28 de abril de1494):

Fianza de Francisco Gómez, librero, hijo de Fernando Gómez. Quedó por fiador de Pedro Serrano.

33. AC. 17 (1495-97), fo 15 (9 de septiembre de 1495):

Licencia de Rodrigo de Escobar, librero, para hacer en unas casas del Cabildo.

34. Id. fo 65 (18 de junio de 1496):

Arriendo de unas casas a Juan, librero. (Ver $\mathrm{n}^{\circ}$ siguiente).

35. Id. fo 72 r (13 de julio de 1496): De Juan librero Portillo. ${ }^{39}$

Fianza de las casas que tiene Juan, librero, y su mujer Catalina de

36. Id. $\mathrm{f}^{\circ} 84 \mathrm{v}$ (7 de septiembre de 1496): Fiança

En Salamanca, miércoles siete de setienbre de XCVI... Pedro de Lilia joyero quedó por fiador de Antonio de la Barreda, librero, por rentas e reparos de las casas e tienda de allende la puente 40 e juró etc. Testigos Diego de Medrano e Antón Bernal e Tristán porque pasó. ${ }^{41}$

37. Id. fo 113 (9 de enero de 1497):

Arriendo de las casas a la Puerta del Río, vacantes por la muerte de Rodrigo de Escobar, librero

38. Id. f 137 (14 de abril de 1497):

Arriendo de unas casas a Lope, librero. ${ }^{42}$

\footnotetext{
37 Dados su apellido y profesión, podría tener alguna relación con Bartolomé de Lila, el flamenco impresor incunable de Coria, vinculado con Salamanca. Su casa pasó a su muerte en 1507 a Juan Francés y a Bernardino de Castronovo, librero (ver AC n ${ }^{\circ} 24, f^{\circ} 221,226$ y 307). Sobre Bartolomé, ver Rodríguez Moñino (Extremadura), Vindel (Arte tipográfico); Odriozola (Historia de la imprenta), J. Delgado Casado, (Diccionario), etc.

${ }^{38}$ En 1498 financió el libro del doctor López de Villalobos, Sumario de la medicina.

${ }^{39}$ Un Diego de Portillo era librero en 1502.

40 Sería ciertamente extraño que Barreda tuviera librería al otro lado del río. Como mucho, casa y almacén. Véase el asiento que sigue.

${ }^{41}$ Entiéndase: porque pasó ante él, Tristán de Urueña, notario.

42 ¿Será Lope Sanz?
}

Titivillus, ISSN 2387-0915, ISSN-e 2603-9966, 2 (2016), pp. 81-105 
39. AC 18, fo 68v (10 de diciembre de 1498):

Gracia concedida a Barreda, librero, por mejoras en las casas frontero del maestrescuela.

40. Id.f ${ }^{\mathrm{O}}$ 68v (10 de diciembre de 1498):

Este dicho día e cabildo fisieron graçia a Barreda, librero, por mejorías que fiso en las casas que tiene al canto casi frontero del maestrescuela, de ciento e veynte mrs. corrientes por mejorías de dos mill mrs. que gastó en un entresuelo segund fisieron fee Pedro Ynperial e Rodrigo de Salamanca. Testigos dichos.

41. AC. 19, fo 75 (19 de marzo de 1501):

Licencia a la hija de Juan de San Vicente para labrar en las casas que tiene enfrente de las Escuelas.

42. AC. $20 \mathrm{f}^{\mathrm{o}} 43$ (15 de diciembre de 1501):

Gracia de cuatrocientos mrs. a Lope, librero, por mejoras en las casas de la calle del Horno de la Canóniga.

43. Id. fo 85 (1 de junio de 1502): Contrato del Cabildo con Bernardino de Castronovo y Antonio de Barreda para imprimir los breviarios salmantinos en Venecia.

En la çibdad de Salamanca, miércoles, primero día del mes de junio, año del nasçimiento de Nro. Salvador Ibsuxpo. de mil e quinientos e dos años, en presençia de mí, Alonso Cornejo, escribano e notario público por las abtoridades apostólica e episcopal e uno de los escribanos e notarios públicos del número de la Yglesia Yglesia Cathredal de la dicha cibdad de Salamanca, e de los testigos de yuso scriptos, estando este dicho día Pedro Ynperial, canónigo en la dicha Yglesia, lugarteniente de deán por don Álvaro de Paz, deán de la dicha Yglesia, y don Álvaro de Salzeda, arcediano de Ledesma, y Pedro Fernández de Toro y Pedro de Palaçios y Françisco Flores y Alonso Gómezy y Françisco Palomeque y Fernando Maldonado y Alonso de Lobera y Gómez González, canónigos en la dicha Yglesia, y Françisco Moreno y Alonso Garcia y Estevan Gutiérrezy el bachiller de Dueñas e Pedro González de Paradinas e Françisco Olivares, raçioneros en la dicha Yglesia, y Françisco Agostin y Pedro de Espinosa y Juan Martinezy Alonso Martinez de Olivença, estando ayuntados en su cabildo hordinario dentro en el cabildo que es en la claustra de la dicha Yglesia, salida de misa de prima, segund lo han de buso e de costunbre, seyendo especialmente llamados a fazer e otorgar lo de yuso escripto por el dicho señor lugarteniente de deán, del qual llamamiento su merçed dio ende fe en presençia de mi el notario e testigos de yuso escriptos, e luego los dichos señores dixeron que por quanto entre ellos ay mucha neçesidad de breviarios deste obispado a cabsa de se aver mandado en mucha manera el diritorio en el sinodo que fizo el muy reverendo yn Xpo. padre e señor don frey Diego de Deza obispo que fue de la dicha çibdad e averse fecho muchos oficios nuevos en los breviarios viejos, ser de mucho gran bolímine e aver muy pocos, por ende dixeron que se concertaban e conçertaron con Bernaldino de Castronovo, milanés, mercader, estante en la dicha çibdad, y con Antonio de la Barreda, mercader, vezino ansi mismo de la dicha çibdad, que presentes

Titivillus, ISSN 2387-0915, ISSN-e 2603-9966, 2 (2016), pp. 81-105 
estaban, para que ellos hiziesen enprimir e ynprimiesen en Veneçia el dicho breviario de la letra del breviario / / que nuevamente se fizo en el Obispado de Çamora ${ }^{43}$ o de otra mejor si a los dichos señores les pareçiere e se les diere y de la manera e forma que se diere por los dichos señores corregido e con las condiciones que tienen tomado a hazer el breviario del Obispado de Plazenciat4 e segund que se les dará más largamente por escripto e los quales sean obligados a enprimir en Veneçia e de los traher dentro del término que están obligados en el Obispado de Plazencia e de los dar encuadernados e segund la contratación e capitulaçión del dicho Obispado de Plazencia e al dicho preçio de ocho Reales de plata, que los dichos señores deán e cabildo sean obligados a tomar dellos çien breviarios e de los pagar conforme a la dicha capitulaçión fasta la dicha quantía de los dichos çien breviarios. Y luego los dichos Bernaldino de Castronovo e Antonio de la Barreda, mercaderes, que presentes estavan, ansi dixeron que otorgavan e otorgaron todo lo suso dicho de suso contenido e ansí dixeron que se obligavan e obligaron por si e por todos sus bienes muebles e Rayzes avidos e por aver ambos a dos de mancomún a voz de uno e cada uno por el todo, Renunciando la ley de duobus Res de vendi y la abténtica presente en todo segund que en ella se contiene de fazer e dar fechos e enpremidos y traher los dichos çient breviarios al preçio e término e con las condiciones e posturas contenidas en la dicha capitulaçión, con tanto que si más enprimieren e traxeren no los puedan vender a persona alguna por tiempo de un año en más presçio de los dichos ocho Reales encuadernados e segund dicho es e so las penas en la dicha capitulaçión contenidas. Y luego los dichos señores deán e cabildo dixeron que obligavan e obligaron los bienes de su mesa capitular, espirituales e tenporales, avidos e por aver, e los dichos Bernaldino de Castronovo e Antonio de la Barreda dixeron que obligavan e obligaron a sy e a todos sus bienes muebles e Rayzes avidos e por aver, de ansi tener e guardar e cunplir todo lo de suso contenido, los unos a los otros e los otros a los otros so la pena de la dicha capitulaçión, la qual pena querian que fuese aplicada e que desde agora la aplicavan para la fábrica e obra de la dicha Yglesia cathredal, para lo qual todo que dicho es ansi tener e mantener e cunplir e pagar e guardar segund dicho es anmas las dichas partes e cada una dellas dixeron que pedian e pidieron e davan e dieron poder cunplido por esta carta a qualesquier juezes e justiçias que fueren, ansi desta çibdad de Salamanca como de otra qualesquier çibdad, villa o lugar que fuesen ante quien dicha carta fuere mostrada $e$ presentada o della fuere pedido cunplimiento de justiçia para que ge lo firieren en todo ansí tener, cunplir, pagar e guardar segund dicho es, procidiento contra las dichas partes e contra qualquier dellas por toda çensura en la questión e remedios del derecho, dando e mandando dar contra ellas sus cartas de descomunión e denunçiaçión e todas las otras que menester fuesen en la dicha razón e faziendo o mandando fazer entrega y esecución en sus bienes, vendiéndolos e rematándolos en pública almoneda o fuera della, e de los maravedís que valieren entregasen o fiziesen pago a la parte que lo oviese de aver ansi de principal como de costas e tanbién e a tan cunplidamente como si los dichos juezes e justiçias o qualquier dellos lo oviesen todo oydo e juzgado e dado por sentençia contra las dichas partes e contra qualquier dellas e a su petiçión e de qualquier dellas e la tal sentençia oviese seydo por ellas consentida e pasada en cosa juggada contra la qual todo que dicho es dixeron que renunciaban e renunçiaron ferias de pan e vino coger presentes e por venir, cartas, merçedes,

${ }^{43}$ Es el no 302 de Odriozola (Catálogo de libros litúrgicos). No se conoce ejemplar.

${ }^{44}$ Es el no 246 de ODriozola. Se conserva ejemplar en París. 
previllegios de Rey o de Reyna o de príncipe o infante o de otro señor o señora qualquier plazos de consejo o de abogado, plazos mudados, días feriados, la demanda en escripto o por palabra e traslado della e desta carta e a todas leys, fueros, derechos e hordenamientos, escriptos e non escriptos, canónicos e çeviles, e toda eseçión de fuerça e de engaño e todas las otras cosas e cada una dellas ansí en general como en espeçial que a una de las dichas partes podrian ayudar e aprovechar e a la otra enpecer sobre la dicha razón y en espeçial dixeron que renunciavan e renunçiaron la ley en que dir. que general renunçiación no vala, de lo qual todo en como pasó anmas las dichas partes e cada una dellas dixeron que pedían e rogaban a mi el dicho notario que fiziese o mandase fazer de lo sobre dicho un ynnistrumento o dos o más e los signase con mi signo e que pedian e rogaban a los presentes que fuesen delo testigos, a lo qual fueron presentes por testigos llamados e rogados: Antón Bernal, portero de la dicha Yglesia, e Diego de Medrano e Juan de Villalón, clérigo, capellán de coro de la dicha Yglesia, vezinos de la dicha çibdad de Salamanca, e Alonso Comejo notario.

44. Id. anejo al $\mathrm{f}^{\mathrm{D}} 108$ :

Las condiçiones e postura con que yo Bernaldino de Castronovo, milanés, librero [añadido entre líneas: e Antonio de la Barreda], comorantes en la çibdad de Salamanca, tomo [añadido: mos] mi cargo sobre mi [nos] de los Reverendos señores deán e cabildo de la Yglesia de Salamanca para hazer ynprimir de molde dentro de la çibdad de Veneçia çiento [blanco] breviarios de la regla e orden del obispado de Salamancat5 que nueva mente han acordado e ordenado e segund el trasunto que los dichos señores o las personas por ellos diputadas me dieren para los ynprimir, son las siguientes:

Primeramente que faré ynpremir del dicho molde los dichos çiento [blanco] breviarios en muy buen papel blanco que no se esparza e de muy buena tinta e muy negra e del tamaño de la letra e de aquella grandeza e grosura de letra e de tamaño de marca e de muy buen bermellón fyno e colorado ansy como está ynpreso e mejor el breviario [tachado: del obispado de Camora que se ynpremió por Juan Antonio Barrera e Françisco Girardino (o Girardingo)] [al margen: Romano inpreso por Paganino de Paganinis Brixien en Veneçia del qual queda un traslado firmado en el arca del cabildo], que tenga en cada coluna de cada plana treynta e quatro renglones e que en la dicha marca sean conpasadas las márgines que quedan inpresas e mejor conpasadas que en el [tachado: de Camora] Romano, no disminuyendo los renglones ni letras ni desengrosándolas en menor cantidad que el [tachado: de Camora] Romano las tiene, syno mejorándolas en letra e conpasando las márgines porque a la margen baxa aya dos cantidades e más de la alta en que las otras lleven su conpás que debe llevar e que la margen [entre líneas: entre las colupnas e la otra] ynterior sea más abiertas e anchas porque el breviario no se abre tanto al abrirlo [tachado: e que la otra margen de medio de las colunas ansy mismo sea más abierta].

Yten que faré corregir el dicho trasumpto que me será dado de malos latines e en la ortografía e de puntos e medios puntos, virgulas e comas etc e de pausas e letras cardinales e

${ }^{45}$ Es el no 249 de Odriozola. Dice que queda un ejemplar incompleto del mismo en la Biblioteca de Santa Genoveva de París (BB $8^{\circ}$ 1298. Inv 1462). No lo veo mencionado en O. Bresson, Catalogue du fonds hispanique (1492-1808) de la Bibliothèque Sainte-Geneviève de Paris, París,1994, tal vez porque no sea impreso español. 
párrafos e letras grandes a donde convenga e las principales que están ylluminadas con sus viñetas como agora se haze.

Yten que porné [-mos] e haré [-mos] poner en principio del breviario a más del calendario su tabla por donde se rija con cuentos de letras e no de alquarismo e que las planas e hojas ansy mismo sus cuentas que digan con la dicha tabla.

Yten que faré titulos encima de cada plana de muy buen bermellón lo que contiene cada plana en suma y los meses.

Yten que los tengo de hazer ynpremir los dichos breviarios en la dicha çibdad de $\checkmark$ eneçia e traellos a la dicha çibdad de Salamanca a mi costa e misión e a todo mi arresto e peligro de cielo e de tierra e del mar desde el día que me fuere dado el dicho trasunto en ocho meses primeros siguientes e darlos corregidos, concertados e linpios e sanos e no mojados ni maculados e enquadernados de cuero de cordován colorado e labrado por çima de fuego e con sus manillas de latón [al margen: de la forma e manera del dicho breviario que queda en el arca del cabildo] $e$ he de aver por cada uno de los dichos breviarios ocho Reales de plata de la moneda de Castilla o dozientos e setenta e dos maravedís de la moneda de Castilla del día que yo los entregare o feziere entregar en la dich a çibdad de Salamanca a los dichos señores o a su mandado fasta treynta dias primeros siguientes segund la cantidad diere dellos enquadernados que ansy se me haga la paga dellos.

Yten que daré a los dichos señores o a quien ellos mandaren fianças en esta dicha çibdad, llanas e abonadas que del día que se me diere el trasunto en los dichos ocho meses primeros siguientes cunpliré todo lo susodicho so pena que pierda veynte mill maravedís para la fábrica de la dicha Yglesia, e que inpremiendo el breviario que daré el dicho trasunto con los dichos breviarios o pagaré por él veynte mill maravedís.

Yten se asentó que los dichos señores paguen de los dichos breviarios los [blanco] e que los otros que los venda yo el dicho Bernaldino a quien quisiere.

[De mano del escribano del cabildo:]

En Salamanca a XVI de agosto de mill e quinientos e dos años, Bernaldino de Castronovo e Antonio de la Barreda, libreros, dixeron que si el cabildo los quisiere inprimir, pues los señores del cabildo estaban conçertados con ellos de tomar çiento briviarios a preçio cada uno de ocho Reales enquadernados e labrados segund en estas condiciones es contenido, que si quisieren tomar quinientos misales que ge los darian a quatroçientos maravedís enquadernados como los breviarios de la letra de los misales que se inprimieron en Veneçia por Lucoantonio de Junta florentín, y los señores doctor Luis González de Medina, Fernando Flores e Pedro de Palaçios e Gómez. González, canónigos, e Francisco de Salamanca, raçionero, que presentes estaban, como diputados para ello por los dichos señores deán e cabildo, dixeron que ellos lo fablarían con los dichos señores e les dirian su respuesta. Testigos, el liçenciado Fernando Rodríguez e Estevan de Montemayor e Alonso Cornejo notario.

Yten este dicho día los susodichos Bernaldino de Castronovo e Antonio de la Barreda, libreros, se obligaron segund la forma de la dicha capitulaçión de traer al dicho tiempo seis briviarios de pergamino para el coro al preçio que le costaren en Veneçia sobre juramento e que si el cabildo no se contentare dellos que se los quedarían ellos para façer dellos lo que quisieren. Testigos dichos. 
Fueles entregado el briviario corregido e concertado de la manera que lo han de traer este dicho día para que de aquí adelante corran los tiempos en la capitulaçión contenidos. Testigos dichos.

45. Id. fo 99 (13 de julio de 1502):

Licencia a la hija de Juan de San Vicente [Elvira de San Vicente] para labrar en sus casas.

46. AC. 21, fo 22 (7 de octubre de1502): Fiança

Este dicho día e cabildo el bedel del studio Alvaro Bedel salió por fiador de la renta e reparos de la casa en que vivia su hermano Jorge librero enfrente de las scuelas que tiene de la Yglesia Juan Álvarez raçionero que fue de la dicha Yglesia, e se obligó etc e juró etc.

47. Id. fo $74 \mathrm{v}$ (27 de enero de 1502):

Fianza de Jorge librero o enquadernador.

48. Id. fo 116v; 117 (10 y 17 de mayo de 1503):

Barreda, librero.

49. Id. fo 118 (19 de mayo de 1503):

Pedro de Barreda, librero o mercader de Salamanca.

50. Id. fo 95r (24 de mayo de 1504):46

En Salamanca este dicho día e cabildo los dichos señores dixeron que mandavan $e$ mandaron al canónigo Pedro Ynperial su mayordomo, que de qualesquier maravedís que toviese de la mesa capitular pagase a Bernaldino de Castronovo librero ochoçientos Reales por rasón de cien briviarios quel dicho cabildo estava obligado a tomar dél a presçio de ocho Reales cada uno e que entregase los dichos cien briviarios al canónigo Francisco Rodríguez:

Yten que el dicho canónigo Francisco Rodríguez repartiese todos los dichos cien briviarios por todas las personas del dicho cabildo e capellanes dél <que $\rangle$ en esta mayordomía estaban o ayan estado en calendario, por cada benefiçiado o capellán un breviario y que tal beneficiado o capellán fuese obligado a pagar los dichos ocho Reales por el dicho breviario dentro de seys días en dinero o en çédula açebtada por el mayordomo y non pagado fuese descontado fasta que pagase e sy algunos más breviarios sobrasen que los toviese e diese cuenta al dicho cabildo e en esto consentieron particularmente todos los que en dicho cabildo se hallaron. Testigos dichos.

51. AC. 22, fo 54 (10 de enero de 1504):

Casas vacantes por muerte de Barreda, librero.

52. Id. Id.:

46 Por tanto, la fecha de impresión sería en los primeros meses de 1504.

Titivillus, ISSN 2387-0915, ISSN-e 2603-9966, 2 (2016), pp. 81-105 
Gracia de mil quinientos treinta mrs. viejos a Elvira de San Vicente, hija de Juan de San Vicente por mejoras hechas en casas del Cabildo, enfrente de las Escuelas.

53. Id. fo 59 (24 de enero de 1504):

Reparo de las casas en que vivía Barreda, librero, a las Escuelas.

54. Id. f 82 (20 de marzo de 1504):

Traspaso de unas casas a Juan de Porras, librero, en la Rúa Nueva.

55. Id. fo 94 (24 de mayo):

Mandamiento del Cabildo al canónigo Pedro Imperial para pagar a Bernaldino de Castronovo, librero, ochocientos reales por los cien Breviarios que encargó el Cabildo, a ocho reales cada uno.

56. Id. $\mathrm{f}^{\mathrm{o}} 133 \mathrm{v}$ (25 de septiembre de 1504): Remate de las casas en Juan de Porras, librero.

Traspaso a Juan de Porras de las casas de Maria Gutierrez, mujer de Bartolomé de Rueda, librero, vecino de Salamanca.

57. Id. fo 167 (23 de diciembre de 1504):

Diego de Madrigal, librero, fiador.

58. AC. $23,47 \mathrm{v}$ (5 de diciembre de 1505): Salamanca.

Alquiler de unas casas a Bernaldino de castronovo, mercader, vecino de

59. Id. f f $^{\mathrm{s}}$ r (1505-1506):

Fianza de Jusquín de Lot, ${ }^{47}$ librero, vecino de Salamanca, de las casas de la Rúa Nueva que tiene Bernaldino de Castronovo, mercader.

60. Id. Id. fo 55 (30 de diciembre de 1505):

Fianza de Juan de Porras, maestro de los moldes, de las casas que tiene Bernaldino de Castronovo. Fiador Jusquin.

II. Libros de Propiedades del Cabildo (van ordenados por calles, casas y arrendatarios sucesivos de las mismas). Nótese que se dejaron desde sus orígenes bienes inmuebles a la Iglesia para asegurar la continuidad de unas rentas que garantizasen la celebración a perpetuidad de memorias y aniversarios, de donde se llegó a la acumulación insostenible (el sistema hizo crisis en el XIX, cuando fueron desamortizados). Pongo algún ejemplo completo para que pueda apreciarse la estructura general de los asientos, el interés del contenido y los datos que pueden recabarse para la historia de la

${ }^{47}$ Sería el conocido Jusquín le Carón.

Titivillus, ISSN 2387-0915, ISSN-e 2603-9966, 2 (2016), pp. 81-105 
librería.48 Los asientos están ordenados por «circuitos», o sea, según el itinerario real o mental del escribano y van siguiendo los sucesivos arrendatarios.

61. ACSA. Cajón 8, Legajo 3, Número 1, f $\mathrm{Xr}$ (1500):

Circuito de las casas que están alderredor de los palaçios obispales e del estudio.

Calle de la Rúa nueva

Unas casas en la dicha calle a la mano yzquierda como van de Santisidro al Desafiadero ${ }^{49}$ que tienen dos puertas; están escriptas en el libro de la Raçión; tiénelas en vida Pero López çapatero por presçio de siete çientos e noventa e çinco mrs. viejos e nueve pares de gallinas. Tomólas por bien reparadas; otorgaron ge las en cabildo a syete de mayo, año de setenta e ocho; pasó por Gonçalo Rodríguez notario; destos tomaron para aniversario uno que se fase VIII ${ }^{\circ}$ ydus februarii e otro IIII ${ }^{\circ}$ kal. Aprilis e otro $I I I^{\circ} \mathrm{kal}$. Maii a cada uno dozientos mrs. viejos. Fiador Juan Sánchez. librero. ${ }^{50}$

Vacó y sacólas Lorenço de León de Dey51 librero.

Compárese con los asientos de los libros siguientes para la misma casa:

62. ACSA 8-3-2, f $\mathrm{Xr}(1509)$ :

Unas casas en la dicha calle como van de Santisidro que tienen dos puertas y aliendan de una parte fasya Sanisidro con la pared de las escuelas mayores y de la otra parte fasya el Desafiadero con casas del Cabildo; están escriptas en el libro de la Raçion; tiénelas por su vida Lorenço de León de Dey librero e ha de dar cada año en renta por ellas dos mill e quinientos mrs. viejos e veynte e çinco pares de gallinas; tomólas por bien reparadas e con las condiçiones de la Tabla ${ }^{52}$ e otorgó contrato bastante en forma de juramento a dos días del mes de dizienbre de mill e quinientos e treze años. Testigos el bachiller Julián Sevillano e Francisco Palomeque portero e Gutierre de Quexada notario. ${ }^{53}$

63. ACSA 8-3-3, fo VIIv:

${ }^{48}$ Para más noticias de todos estos libreros que llegaron a ver el siglo XVI, ver mi Guía documental del mundo del libro Salmantino del siglo XVI, Segovia, 2006.

${ }^{49} \mathrm{La}$ iglesia de San Isidro estaba (y está, aunque no como iglesia) al comienzo de la Calle de los Libreros; el Desafiadero estaba en la parte de abajo, al poniente, de dicha calle, más allá de la Universidad.

${ }^{50}$ Un hijo de Diego Sánchez de Cantalapiedra se llamaba Juan. ¿Lo sería éste Juan Sánchez?

${ }^{51}$ Los Liondedei era una familia de libreros italianos originaria de Péssaro.

${ }^{52}$ Es la Tabla de arriendos que estaba colgada en la Sala Capitular y que se conserva; véase una entrada: Otrosy con condición que ansy las casas que se arriendan por sy solas como las que se arriendan con otra beredad las tome por fechas e bien reparadas e que asy se obligue de las tener e mantener durante el tiempo del arrendamiento cabe las dexar fechas e bien reparadas al tiempo que vaque en qualquier manera...

53 En AC. Libro 25, f $\mathrm{f}^{\mathrm{O}} 222 \mathrm{v}$ (1515): Traspaso de unas casas y gracia a Lorenzo de Liondedei por muerte de Perucho librero.

Titivillus, ISSN 2387-0915, ISSN-e 2603-9966, 2 (2016), pp. 81-105 
Unas casas en la Rúa Nueva como van de Santisidro al Desafiadero a la mano izquierda junto con los Palacios Obispales. Son de capellanías del coro. Lorenço de Leon de Dey las tiene en vida... Otorgáronseles en Cabildo a seys días de octubre de mill e quinientos e veinte e nueve años. Fiador Andrea de Leon de Dey su hijo.

- Juan Vázquez, enquadernador, sacó estas casas por muerte del dicho Lorenço de León de Dey a XXI de mayo de 1535 años.

- En XXI de mayo de 1535 años el dicho Juan Várquez traspasó estas casas en Francisco de Portonaris, hijo de Jácome de Portonaris. Fiador Guillermo de Minis [Millis] y Pierres de Cos [Cros] libreros.

- Otras casas linderas que solían andar todas en una Renta asta que vacaron por muerte del dicho Lorenço de León de Dey.

- Francisco de Portonaris, hijo de Jácome de Portonaris sacó estas casas por muerte del dicho Lorenço de León de Dey... por traspasaçión que de ellas le hizo Juan Vázquez. enquadernador, que las habia sacado a XXI de mayo de 1535... Fiador Guillermo de Minis librero e el dicho Juan Vázquez enquadernador, veçinos de Salamanca e Pierres de Cros librero.

- Antón Cañedo, sastre, veçino de Salamanca, sacó estas casas que se echaron en quiebra porque no pagaba Domingo de Portonaris y por estar fuera del Reyno... otorgáronselas en Cabildo a tres días de abril de mill e quinientos e çinquenta y quatro años.

64. ACSA 8-3-1, fo XIv: Juan librero (tal vez el Juan Sánchez, librero, fiador en1478).

Plaza de Santa María (Catedral)

65. $\mathrm{F}^{\mathrm{o}}$ XIIIv: Alonso Nieto librero (1506). ${ }^{54}$

66. $\mathrm{F}^{\mathrm{o}} \mathrm{XIVv}$ : Antonio de Salvatierra librero (1505). ${ }^{55}$

67. $\mathrm{F}^{\mathrm{O}} \mathrm{XVv}$ : Unas casas en la dicha calle Plaza de Santa María, o de la Catedral], frontero de las escuelas que tienen una tienda de libros, son de la Raçión, tiénelas en vida Elvira Ruiz, hija de Juan de Sant Viçente, 56 por presçio de quatro myll e dozientos mrs. viejos e quarenta e dos pares de gallinas, tomólas por bien reparadas, otorgaron ge las en cabildo a veinte dias de setienbre año de mill e quatroçientos e noventa e quatro años. Fiador su marido e Juan de Sant Viçente su padre, e pasó por Alonso Cornejo notario.

Ovo graçia por mejorías que en ellas fiço de seys çientos e treynta mrs. viejos a doçe días de setienbre año de noventa e seys, pasó por Alonso Cornejo notario.

\footnotetext{
54 Alonso Nieto, librero, casado con Juana González, murió el 3 de octubre de 1539.

55 Este librero vivía en la Plaza de la catedral, murió el 14 de enero de 1533.

56 No se olvide: uno de los primeros libreros-impresores, cf. supra. Elvira estaba casada con un Bartolomé de Francaforte (Frankfurt ?) y muerió el 10 de enero de de 1511 (AC. $\left.24, f^{\circ} 91 v\right)$
} 
Ovo graçia de myll e quinientos e treynta mrs. viejos por mejoríasque en ellas fiço. Otorgó fee en cabildo a doze días de henero de quinientos e quatro, pasó por ante Alonso Cornejo notario.

Yten ovo graçia la dicha Elvira Ruiz, de quinientos mrs. viejos e çinco pares de gallinas e le fue fecha en cabildo por algunas cabsas, lo qual se fiço a quatro días de agosto de quinientos e ocho años. ${ }^{57}$ Por ante Gutierre Quexada notario.

68. $\mathrm{F}^{\mathrm{o}}$ XVIIIv y ss: Juan de Porras, librero, tenía tres casas del Cabildo que daban a la Rúa Nueva y dos a la Calle Traviesa, ${ }^{58}$ que pasaron a Gonzalo de la Rúa el 20 de diciembre de 1501 y después a Blas de Vergara, librero, el 21 de julio de 1516; otra a Pero Ordóñez, organista, el 21 de octubre de 1527; otra a Cristóbal Sánchez, sastre, el 22 de noviembre de 1527; otra a Juan de Junta, librero el 9 de diciembre de 1527, y la última a Miguel de la Peñuela, sastre, el 13 de noviembre de 1528. Luego Juan de Porras tuvo que morir hacia finales del verano, o en octubre, de 1527 (y nacer hacia 1465).

Dichos asientos se comprenden perfectamente con sólo patear / imaginar los lugares actuales (la topografía sigue siendo casi la misma): Juan de Porras fue arrendando al Cabildo desde 1491 las casas que iban desde la calle Traviesa (dos puertas) y calle Libreros (tres puertas) hasta el callejón que salía enfrente de la puerta misma de la Universidad, a lo largo del Hospital del Estudio (hoy Rectorado) hasta la entrada del patio de las Escuelas Menores, porque entonces no existía el actual patio de las Escuelas Mayores (que se abrió a comienzos del XVII). Puede pensarse que a partir de 1491 Juan de Porras, tras instalarse independiente, ya no trabajaba con su socio Juan de Montejo.

69. $F^{o}$ LXXVIIr: Gabriel sedero o librero que agora se llama vivía en 1497 en la Calle Traviesa; era fiador Juan de Porras. Vacaron las casas en 1517 (fecha probable de la muerte de Gabriel).

70. Libro de Propiedades del Cabildo: Cajón 8, Legajo 3, Número 2, fo LXXIXr:

Bernardino de Castronovo, ${ }^{59}$ librero, vivía en 1505 en la Rúa Nueva; eran sus fiadores Jusquín [Lecarón], librero, y Juan de Porras, librero; vacaron y pasaron al canónigo Esteban Gutiérrez de Bobadilla el 5 de setiembre de 1512.

71. Fo LXXXv: Rúa Nueva. Son dos casas con su bodega e ocho cubas de tener vino e un tonel que fasen trezientas e treynta medidas e una tinaja de tener pan. Son de Capellanías. Tiénelas en vida el maestro Antonio de Lebrixa por presçio de tres mill e ochoçientos mrs. viejos e treynta e ocho pares de gallinas. Tomólas por bien reparadas,

\footnotetext{
${ }^{57}$ En 1511 «estas casas que tienen tienda de libros» las tenía el canónigo Alonso de Segura.

58 Sigue llamándose así. Es perpendicular a la Calle de los Libreros, hacia el Norte.

${ }^{59}$ Milanés; suegro de Guillermo de Millis; murió en 1530.
} 
otorgaron ge las en cabildo a tres días de marco año de setenta e nueve. Fiador don Juan de Fonseca ${ }^{60}$ obispo de Córdova e Sancho Montesino. ${ }^{61}$ Pasó por Alonso Cornejo notario.

En 21 de julio de 1522 pasaron a Alejando de Cánova, librero, en çinco mill e quinientos e diez mrs. viejos e çinquenta e çinco pares de gallinas vivas (Fue testigo Jusquín, librero, y fiador Bautista de Asula, librero). ${ }^{62}$ Extracto.

III. Libro de Fábrica. Leg. 5. Cajón 44, no 1. Comienza en año 1499.

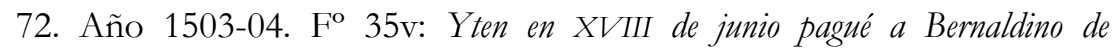
Castronovo librero por quatro breviarios de pergamino para el coro honze mil mrs.

CODA: El asunto Nebrija o Nebrija en este asunto.

Todo hace pensar que fue el agustino fray Jerónimo Román en su Repúblicas del mundo (Medina del Campo, Francisco del Canto, 1575), pero leído en Pérez Pastor, La imprenta en Medina, quien recoge la «curiosidad» en los añadidos a la descripción bibliográfica del ejemplar, el que dio «la idea»a Proctor, Haebler, Norton y sucesores en el asunto del Nebrija dueño del taller o talleres anónimos salmantinos. Hablaba el buen fraile de los orígenes chinos (incluso bíblicos) de la imprenta (con planchas xilo- o calcográficas), y añadía: «Esto se puede decir lícitamente porque en la officina del maestro Antonio de Lebrixa parecen ciertas láminas de metal con todas las letras necessarias, y se imprimieron artes con ellas...» De ahí, el benemérito Francisco Vindel (El arte..., p. XXIs), con su apasionamiento habitual, ya titulaba capítulo: «El taller anónimo de Salamanca pertenecía o era dirigido por Antonio de Nebrija», y hasta le atribuyó una marca de impresor, basándose en cinco razones (más o menos razonables). Digamos solamente (para todos ellos) que officina no significaba, ni significa, «taller de imprenta», sino «el lugar donde se desempeña el propio officium» o lugar de trabajo, el que fuera, «taller, tienda o despacho», y que sólo puede significarlo en sentido estricto cuando lo es la de un impresor. O sea, «oficina de Nebrija» (si algún sentido tiene) no es lo mismo que «imprenta de Nebrija», pero sí lo sería «oficina de Portonaris» e «imprenta de Portonaris», pongamos por caso. Ahora bien, nada excluye el hecho de que el Nebrisense, para debelar la barbarie, se dedicase - a mayores- a imprimir abecedarios y cartillas («artes») mediante dichas

\footnotetext{
${ }^{60}$ De don Juan de Zúñiga, sobrino de don Alonso de Fonseca, arzobispo de Sevilla, había sido Nebrija ayo y preceptor, después secretario. El discípulo murió, también de arzobispo de Sevilla, el 26 de julio de 1504.

${ }^{61}$ Sancho Montesinos, padre de Isabel de Solís, esposa de Nebrija. Un hijo de Nebrija se llamó Alonso Montesinos, caballero de Santiago.

62 Nebrija había tomado en arriendo estas casas al Cabildo en 1479, posiblemente al, o para, contraer matrimonio y perder su condición clerical. Melius est nubere quam uri había dicho él mismo. Vid F. G. Olmedo, S.I., Nebrija (1441-1522), Madrid, 1942, p. 25.
} 
«láminas de metal», cosa que sí entra dentro de los límites de lo razonable (y el hallar las dichas cartillas de lo deseable).

No debe olvidarse tampoco que el Maestro sólo vivió en Salamanca durante los cursos que van de 1473-74 a 86-87 (la casa le fue alquilada por el Cabildo el 3 de marzo de 1479; cf. doc. no 61) y de 1505-06 a 12-13; entre 1487 y 1505 anduvo como secretario de Zúñiga por Zalamea y Sevilla. Véase el siguiente asiento de las Actas Capitulares, $\mathrm{n}^{\circ} 13$ (1488-89), fo 65r: Liçencia.

En Salamanca, viernes XXVI de febrero de noventa años, estando D. Alonso de Pa\%, deán... dieron licencia al maestro de Librixa para traspasar unas casas que tiene de los dichos señores [del Cabildo] a la Rúa Nueva al Dotor de la Reyna...

Serían las casas que se le habían alquilado el año anterior y que traspasó al ausentarse de Salamanca. Este Doctor de la Reina (Isabel la Católica) era D. Fernán Álvarez Abarca o Fernando Álvarez de la Reyna, físico, quien casado con $\mathrm{D}^{a}$ Beatriz de Alcaraz, fueron padres de Ana de Abarca, la que casada a su vez con Francisco Maldonado, el Comunero (hijo de Rodrigo Arias Maldonado), lo fueron también de otro Rodrigo Arias Maldonado (casado con Ginebra de Acuña) y de Fernán Álvarez Abarca.

Sin embargo, por otro documento capitular de 1508 (AC. 24, fo 263 y 333), sabemos que el Cabildo dio licencia al Maestro Lebrixa para faser çierta tienda de libros que quiere faser. ${ }^{63}$ ¿Para ser librero de sus propios libros justo al lado de las Escuelas? ${ }^{34}$ ¿Para realquilar la casa a otros libreros? Probablemente para ambas cosas. Veamos:

AC. 25 (1519), f $\mathrm{f}^{\mathrm{O}}$ 388: Fianza de Lorenzo de Parada de la renta y reparos de las casas que tiene ad vitam el maestro Nebrija, donde vive Bautista de Asula, librero, vecino de Salamanca. (Véase además doc. 77 supra).

En cualquier caso, en 1508 ya no le quedaban al Maestro muchos años de vida salmantina. En 1513 pasó a Alcalá por el infausto asunto de la cátedra, como se ha referido tantas veces, o por ver mayores alicientes junto al Cardenal Cisneros y a Guillén de Brocar, afanados para entonces en la Políglota Complutense. Y complutense sería su fallecimiento y tránsito el 2 de julio de 1522. Lo que, en definitiva, puede certificarse es que su casa fue traspasada en su ausencia y ocupada por la familia Abarca, tal vez mientras se construía su casa-palacio, la hoy llamada de los Abarca-Maldonado, y después por libreros, dada su estratégica posición frente a la Universidad. A partir 1513

\footnotetext{
63 Véase M. GARCía BlanCO, «La casa del humanista Antonio de Nebrija en Salamanca», Emerita 13, 1945, 17-40 (y en Id., Seis estudios salmantinos, Salamanca, 1961, 31-51).

${ }^{64}$ Nebrija no se mantuvo ajeno al mundo de la imprenta, como ya supuso NORTON; lo tratamos más por extenso en «Nebrija y los orígenes de la tipografía griega en España», en C. Codoñer y J. A. González Iglesias (eds.), Antonio de Nebrija: Edad Media y Renacimiento, Salamanca, 1994, 537-547.
}

Titivillus, ISSN 2387-0915, ISSN-e 2603-9966, 2 (2016), pp. 81-105 
estuvo ocupada por el italiano Bautista de Asula y tal vez Juan de Junta. ${ }^{65}$ Muerto Nebrija, pasó a Alejandro de Cánova el 21 del mismo mes.

Pero lo más importante es que ahora podrían admitirse nueva fichas; como esta:

Nebrija, A. de: Introductiones latinae, Salamanca, Diego Sánchez de Cantalapiedra y Alfonso de Porras, 1481.

Y lo mismo para los Reportorios de pragmáticas sanciones (Haebler, $\mathrm{n}^{\circ} 211$ ), Cortes de Toledo ( $\mathrm{n}^{\circ}$ 354), Sinodales de Ávila ( $\mathrm{n}^{\circ}$ 629), todos con ejemplares conocidos. Y probar los Breviarios de Salamanca.

En fin, lo demás de esta materia se quedará para los señores bibliógrafos.

65 AGS. Registro General del Sello, Septiembre de 1514: «Bautista de Asula e Juan de Junta, libreros de Salamanca» (le son retenidas sus balas de libros importadas en Cádiz).

Titivillus, ISSN 2387-0915, ISSN-e 2603-9966, 2 (2016), pp. 81-105 